\title{
Importância do consumo de café da manhã para ingestão de vitamina $D$ em crianças de Viçosa-Minas Gerais
}

Luana Cupertino Milagres, Naruna Pereira Rocha, Ana Paula Pereira Castro, Mariana de Santis Filgueiras, Fernanda Martins de Albuquerque, Juliana Farias de Novaes

\begin{abstract}
Resumo
O café da manhã é uma refeição importante e está associada a ingestão de nutrientes importantes para o crescimento. No entanto, poucos estudos examinaram a contribuição de consumo de café da manhã para a ingestão de vitamina $\mathrm{D}$. Avaliar a relação entre o hábito de realizar o café da manhã e o consumo de vitamina D. Trata-se de um estudo transversal realizado com 268 crianças de 8 e 9 anos matriculadas em todas as escolas públicas urbanas de Viçosa, MG. Foram avaliadas características socioeconômicas e demográficas. O consumo alimentar foi avaliado por 3 recordatórios alimentares de 24 horas, obtidos em dias não consecutivos, sendo uma das avaliações referente ao fim de semana. A análise estatística foi realizada no software SPSS versão 20, e o nível de significância adotado foi de 5\%. Dois grupos foram comparados quanto ao hábito de realizar o café da manhã. Este estudo foi aprovado pelo Comitê de Ética em Pesquisa com Seres Humanos da Universidade Federal de Viçosa. Houve uma prevalência de 50\% do sexo feminino. A média da concentração sérica e da ingestão de vitamina D nas crianças foi $29,5 \mathrm{ng} / \mathrm{mL}$ e $1,66 \mu \mathrm{g} / \mathrm{dia}$, respectivamente. Nenhuma criança atingiu a recomendação de ingestão de vitamina $\mathrm{D}$ e $22 \%$ não apresentaram o hábito de realizar o café da manhã todos os dias. O não consumo de café da manhã não diferiu entre as idades $(\mathrm{p}=0,648)$ e os $\operatorname{sexos}(\mathrm{p}=0,302)$. As crianças que não realizaram o café da manhã todos os dias apresentaram menor ingestão de vitamina $\mathrm{D}$ e menor prevalência de ingestão maior que a mediana, além de maior renda per capita $(\mathrm{p}<0,05)$. A vitamina $\mathrm{D}$ sérica não diferiu entre os grupos. A ingestão de vitamina $\mathrm{D}$ foi positivamente correlacionada com o número médio de refeições por dia $(r=0,209, p=0,001)$. Os resultados do presente estudo apoiam a hipótese de que o consumo de café da manhã em crianças estaria associada a uma maior ingestão de vitamina $\mathrm{D}$, embora não tenha apresentado associação com a concentração sérica de $25(\mathrm{OH}) \mathrm{D}$. Um fato preocupante foi que nenhuma criança atingiu a recomendação de ingestão de vitamina $\mathrm{D}$ sendo importante a implementação de ações de educação alimentar e nutricional para incentivar o hábito do consumo do café da manhã, principalmente em crianças de famílias com maior poder aquisitivo.
\end{abstract}

Descritores: Vitamina D, Café da manhã, Crianças. 